\title{
Impaired ATP-Induced Coronary Blood Flow and Diminished Aortic NTPDase Activity Precede Lesion Formation in Apolipoprotein E-Deficient Mice
}

\author{
Nathalie Mercier, ${ }^{*}$ Tuomas O. Kiviniemi, ${ }^{\dagger \neq}$ \\ Antti Saraste, ${ }^{\ddagger}$ Mari Miiluniemi, ${ }^{*}$ Johanna Silvola, ${ }^{\ddagger}$ \\ Sirpa Jalkanen, ${ }^{*}$ and Gennady G. Yegutkin* \\ From the Medicity Research Laboratory and the Department of \\ Medical Microbiology, University of Turku, Turku; the \\ Department of Clinical Physiology, ${ }^{\dagger}$ Turku University Hospital, \\ Turku; and the Department of Medicine and Turku PET Centre, ${ }^{*}$ \\ Turku University Hospital, Turku, Finland
}

Intravascular ATP and ADP are important regulators of vascular tone, thrombosis, inflammation, and angiogenesis. This study was undertaken to evaluate the contribution of purinergic signaling to disturbed vasodilation and vascular remodeling during atherosclerosis progression. We used apolipoprotein $\mathrm{E}-$ deficient $\left(A p o e^{-/-}\right)$mice as an appropriate experimental model for atherosclerosis. Noninvasive transthoracic Doppler echocardiography imaging with adenosine, ATP, and other nucleotides and nonhydrolyzable P2 receptor agonists and antagonists suggests that ATP regulates coronary blood flow in mice through activation of P2Y (most likely, endothelial ATP/UTP-selective $\mathbf{P 2} \mathrm{Y}_{2}$ ) receptors, rather than via its dephosphorylation to adenosine. Strikingly, compared to age-matched wild-type controls, young (10- to 15week-old) $A p o e^{-/-}$mice displayed diminished coronary reactivity in response to ATP but not adenosine. The impaired hyperemic response to ATP persisted in older (20- to 30-week-old) $A$ poe ${ }^{-/-}$mice, which were additionally characterized by mild atherosclerosis (as ascertained by aortic Oil Red $O$ staining) and a systemic increase in plasma ATP and ADP levels. Concurrent thin-layer chromatographic analysis of nucleoside triphosphate diphosphohydrolase (NTPDase) and ecto- $5^{\prime}$-nucleotidase/CD73 activities in thoracic aortas, lymph nodes, spleen, and serum revealed that aortic NTPDase was decreased by $40 \%$ to $50 \%$ in a tissue-specific manner both in young and mature $A p o e^{-/-}$mice. Collectively, disordered purinergic signaling in $A p o e^{-/-}$mice may serve as important prerequisite for impaired blood flow, local accumulation of ATP and ADP at sites of atherogenesis, and eventually, the exacerbation of atherosclerosis. (Am J Pathol 2012, 180:419-428; DOI: 10.1016/j.ajpath.2011.10.002)

Atherosclerosis is a chronic inflammatory disease of the arterial wall. The pathogenesis of atherosclerosis is a complex and systemic process involving a dysfunction of vascular endothelium, proliferation of smooth muscle cells (SMC), cholesterol accumulation, altered secretion of chemokines, recruitment of inflammatory cells, adhesion of activated platelets, and thrombus formation. ${ }^{1-3}$ Unlike humans, mice are quite resistant to atherosclerosis as a result of high levels of high-density lipoprotein and low levels of pro-atherogenic low-density lipoprotein and very low-density lipoprotein. Apolipoprotein E (ApoE) is an important component of triglyceride-rich lipoproteins with multiple functions, particularly involved in transport of chylomicrons and very low-density lipoprotein remnants with both endogenous and dietary triglycerides and cholesterol to the liver and other extrahepatic tissues. ${ }^{4}$ Targeted deletion of this glycoprotein triggers the development of spontaneous hypercholesterolemia and atherosclerotic lesions in Apoe ${ }^{-1-}$ mice, with a cellular composition remarkably similar to that of humans. ${ }^{5-7}$ Mice lacking low-density lipoprotein receptor (LDLR) represent another widely used model of atherosclerosis with relatively mild hyperlipidemia and lesion progression, which can be markedly acceler-

Supported by grants from the Academy of Finland, the Sigrid Juselius Foundation, and also the Turku Collegium for Science and Medicine of University of Turku (A.S.) and European Union Marie Curie fellowship (351/702/58514 to N.M.).

Accepted for publication October 4, 2011.

N.M., T.O.K., and A.S. contributed equally to this study.

Supplemental material for this article can be found at http://ajp. amjpathol.org or at doi: 10.1016/j.ajpath.2011.10.002.

Current address of N.M., INSERM, U961, Nancy, F-54505 France; University of Nancy, Nancy, F-54505 France.

Address reprint requests to Gennady G. Yegutkin, Ph.D., MediCity Research Laboratory, University of Turku, Tykistökatu 6A, 20520 Turku, Finland. E-mail: genyeg@utu.fi. 
ated by feeding a high-fat diet. ${ }^{7}$ Although murine models have proved useful to study the pathophysiology of atherosclerosis, the peculiarities in cholesterol metabolism and lipid profile, different locations of atherosclerotic plaques (aorta in mice versus coronary arteries in humans), and a relative lack of lesion progression leading to myocardial infarction and cardiac dysfunction might hinder the translation of the findings from mice to humans. ${ }^{6,7}$

The evolving view of atherosclerosis as a metabolic complication has directed attention toward extracellular nucleotides, important players in cardiovascular pathophysiology. ${ }^{8-10}$ Evidence is accumulating that SMC, as well as vascular endothelial and blood cells, can release ATP and other nucleotides (ADP, UTP) in response to blood flow changes, hypoxia, and other inflammatory stimuli. 2,10,11 The final outcome of purinergic stimulation depends on the integration of diverse responses elicited by ligand-gated (P2X) or G protein-coupled (P2Y) receptors expressed on various cell elements within the vessel wall, as well as subsequent nucleotide metabolism by membrane-bound ectoenzymes. ${ }^{11}$ Targeted deletion of key inactivating enzymes, ecto-nucleoside triphosphate diphosphohydrolase1 (NTPDase1, alias CD39) ${ }^{12-15}$ or ecto-5'-nucleotidase/CD73, ${ }^{16}$ was shown to be accompanied by disordered hemostasis, thromboregulation, vascular inflammation, and pathological angiogenesis. Studies with mice lacking a particular connexin (a large family of transmembrane proteins co-expressed with pannexins and forming hemichannels or gap junctions) revealed increased leukocyte-endothelial adhesion and development of aortic lesions in connexin $37^{-/-} \mid \mathrm{Apoe}^{-/-}$ double knockout mice ${ }^{17}$ as well as in mice with targeted endothelial deletion of connexin $40,{ }^{18}$ which occurred due to impaired ATP release by monocytes and decreased endothelial ecto-5'-nucleotidase/CD73 activity, respectively.

Disturbed vasodilation is thought to predispose to vascular remodeling and arterial injury at various pathological states, including atherosclerosis and hypertension. ${ }^{10,19,20}$ By using noninvasive transthoracic Doppler echocardiography (TTDE) imaging, significantly impaired coronary blood flow was detected in old, severely atherosclerotic $A p o e^{-/-}$mice in response to maximal vasodilation induced by the purinergic agent adenosine ${ }^{21}$ or anesthetic drug isoflurane, ${ }^{22}$ as well as in double knockout mice deficient in LDLR and ApoB48 (truncated form of lipoprotein ApoB100 responsible for very low-density lipoprotein-mediated cholesterol clearance in mice) during infusion of adenosine. ${ }^{23}$ This study was undertaken to identify the role of intravascular purines in control of coronary blood flow in $A p o e^{-/-}$mice prone to the disease but still essentially normal. The results obtained demonstrate that vasodilatory responses to ATP, but not adenosine, are impaired in young $A p o e^{-1-}$ mice that, in conjunction with disordered aortic nucleotide homeostasis, might represent the critical initiating event in pathological vascular remodeling and atherogenesis.

\section{Materials and Methods}

\section{Animals}

Female and male $\mathrm{Apoe}^{-/-}$mice on the C57BL/6 background, purchased from Jackson Laboratories (West Grove, PA), and age-matched wild-type C57BL/6 controls were used in the experiments. Mice were kept in the Central Animal Laboratory in the University of Turku, raised in pathogen-free conditions, and fed with standard low-fat mouse chow. The animals were used in the experiments at age 10 to 15 weeks (young) and age 20 to 30 weeks (mature adult). All procedures were performed according to protocols approved by the Animal Ethics Committee, University of Turku, and in compliance with the law and the Statute on Animal Experimentation in Finland.

\section{Doppler Echocardiography}

TTDE was performed with an Acuson Sequoia mainframe (Siemens Acuson, Mountain View, CA) and a $15-\mathrm{MHz}$ linear transducer (15L8). Mice were anesthetized in a closed chamber with $3 \%$ isoflurane in oxygen, placed in the supine position, and kept in normothermia fully sedated with $1.4 \%$ isoflurane. Flow in the descending left coronary artery was localized, and its course followed under color Doppler mapping in the anterior wall of the left ventricle using modified long-axis views. Ultrasound beam and flow were aligned as close to parallel as possible. Saline solutions of adenosine (ITEM Development, Stocksund, Sweden), ATP, ADP, AMP, UTP (sodium salts, all from Sigma, St. Louis, MO), as well as adenosine-5'-( $\gamma$-thio)-triphosphate (ATP $\gamma \mathrm{S})$ and $2^{\prime}\left(3^{\prime}\right)-\mathrm{O}-(4-$ benzoylbenzoyl)adenosine-5'-triphosphate (BzATP) (Tocris Bioscience, Bristol, UK) (40 to $400 \mu \mathrm{g} / \mathrm{mL}$ ) were infused intravenously via the tail vein for $\sim 2$ minutes with an infusion pump at the flow rate of $0.6 \mathrm{~mL} /$ hour (dose range: 16 to $160 \mu \mathrm{g} \cdot \mathrm{kg}^{-1} \cdot \mathrm{min}^{-1}$ ). In some assays, the mice were pre-treated for 3 minutes with P2 antagonists pyridoxalphosphate-6-azophenyl-2', 4'-disulfonic acid (PPADS; Tocris Bioscience) and suramin (ICN Biomedicals, Aurora, $\mathrm{OH}){ }^{8}$ before infusion of ATP. Heart rate, diastolic peak, and mean flow velocities were measured both at rest and during the infusion of vasoactive compounds. Coronary flow reserve (CFR) was calculated as the ratio of mean velocities before and during hyperemia, as described previously. ${ }^{23}$ Images were stored in a digital image archive (Kinet DX, Acuson Siemens) and analyzed later offline while blinded to the study groups. All measurements were calculated as means of three cardiac cycles.

\section{Tissue Preparation}

Mice were sacrificed with carbon dioxide. Blood was collected from the heart to prepare serum and EDTA plasma. Thoracic aortas were dissected from the brachiocephalic trunk to the iliac bifurcation and then rinsed thoroughly with cold phosphate-buffered saline solution (PBS) to remove any blood components. For enzymatic 
assays, aortas were excised, homogenized in $1 \mathrm{mmol} / \mathrm{L}$ $\mathrm{KH}_{2} \mathrm{PO}_{4}$ buffer $(\mathrm{pH}$ 7.4) supplemented with $0.25 \mathrm{~mol} / \mathrm{L}$ sucrose with an Ultra-Turrax homogenizer (Janke and Kunkel GmbH, IKA-Laboratortechnik, Staufen, Germany) and stored at $-70^{\circ} \mathrm{C}$. In some experiments, the aortas were divided into two segments. One part was directly homogenized to obtain total homogenate, whereas another half was cut open longitudinally and incubated for $\sim 1$ minute with Dispase (50 U/mL; BD Biosciences, San Jose, CA). The detached endothelial cells were then gently scraped, washed, and then resuspended in RPMI 1640 medium. Endothelial-denuded medium consisting of SMC was carefully separated from the adventitia, and both fractions were homogenized in RPMI 1640. Protein concentration was determined by BCA Protein Assay Kit (Pierce, Rockford, IL), according to the manufacturer's instructions. Single-cell suspensions were also isolated from peripheral (pooled auxiliary and inguinal) lymph nodes and spleen, as described elsewhere. ${ }^{24}$

\section{Enzyme Histochemistry and Oil Red O Staining}

For localization of nucleotidase activities, a modification of the lead nitrate $\left[\mathrm{Pb}\left(\mathrm{NO}_{3}\right)_{2}\right]$ method was used. ${ }^{25}$ In brief, frozen aortic sections were thawed to room temperature and pre-incubated for 45 minutes in Trizma-maleate sucrose buffer $[40 \mathrm{mmol} / \mathrm{L}$ Trizma maleate, $0.25 \mathrm{~mol} / \mathrm{L}$ sucrose, $(\mathrm{pH} 7.4)]$ supplemented with the alkaline phosphatase inhibitor levamisole $(2 \mathrm{mmol} / \mathrm{L})$. The enzyme reaction was then performed for 60 minutes at room temperature in Trizma-maleate sucrose buffer-buffered substrate solutions containing $2 \mathrm{mmol} / \mathrm{L} \mathrm{Pb}\left(\mathrm{NO}_{3}\right)_{2}$ and one of the following substrates: ATP (300 $\mu \mathrm{mol} / \mathrm{L})$, ADP (300 $\mu \mathrm{mol} / \mathrm{L})$, or AMP (1 mmol/L). In blank specimens, the substrate was omitted from the incubation solution. The lead orthophosphate precipitated in the course of nucleotidase activity was visualized as a brown deposit by incubating sections in $0.5 \%\left(\mathrm{NH}_{4}\right)_{2} \mathrm{~S}$ followed by three washes in Trizma-maleate sucrose buffer for 3 minutes each. Tissue sections were also stained with hematoxylin and eosin. Slides were mounted with Vecta Mount (Vector Laboratories, Burlingame, CA), and images were acquired using an Olympus BX60 microscope (Tokyo, Japan). For quantification of the lesion size, aorta was stained with Oil Red $\mathrm{O}$ after fixation with $4 \%$ paraformaldehyde, and the ratio of atherosclerotic to total area was calculated using Quancoul image analysis software (Quant'Image, Bordeaux, France).

\section{Thin Layer Chromatographic Analysis of Purine- Converting Activities}

Standard assays were performed at $37^{\circ} \mathrm{C}$ in a final volume of $80 \mu \mathrm{L}$ of RPMI 1640 medium containing total aortic homogenate (or its particular fraction) as enzyme source, $4 \mathrm{mmol} / \mathrm{L} \beta$-glycerophosphate, various unlabeled nucleotides, and tracer $\left[2,8-{ }^{3} \mathrm{H}\right]$ ATP (PerkinElmer, Boston, MA), [2,8- $\left.{ }^{3} \mathrm{H}\right]$ ADP (PerkinElmer), or [2- $\left.{ }^{3} \mathrm{H}\right] \mathrm{AMP}$ (Quotient Bioresearch, GE Healthcare, Rushden, UK) as appropriate substrates. For ATPase and ADPase assays,
$0.4 \mu \mathrm{g}$ of aortic homogenate was incubated for $60 \mathrm{~min}$ utes with $400 \mu \mathrm{mol} / \mathrm{L}\left[{ }^{3} \mathrm{H}\right] \mathrm{ATP}$ and $\left[{ }^{3} \mathrm{H}\right] \mathrm{ADP}$, respectively. $5^{\prime}$-Nucleotidase was assayed by incubating $3 \mu \mathrm{g}$ of homogenate for 60 minutes with $300 \mu \mathrm{mol} / \mathrm{L}\left[{ }^{3} \mathrm{H}\right] \mathrm{AMP}$. For detecting adenylate kinase and nucleoside $5^{\prime}$-diphosphate kinase (NDPK), $1.5 \mu \mathrm{g}$ of homogenate was incubated with $400 \mu \mathrm{mol} / \mathrm{L}\left[{ }^{3} \mathrm{H}\right] \mathrm{AMP}$ (for 45 minutes) or $\left[{ }^{3} \mathrm{H}\right]$ ADP (for 15 minutes) in the presence of $750 \mu \mathrm{mol} / \mathrm{L}$ $\gamma$-phosphate-donating ATP. Radiolabeled nucleotides and nucleosides were then separated by thin layer chromatography (TLC) using Alugram SIL G/UV 254 sheets (Macherey-Nagel, Duren, Germany) and quantified by scintillation $\beta$-counting, as described elsewhere. ${ }^{26}$ For autoradiographic analysis, aortic homogenates $(0.4 \mu \mathrm{g}$ of protein) were also incubated for 30 minutes with 50 $\mu \mathrm{mol} / \mathrm{L}\left[\gamma^{-}{ }^{32}\right.$ P]ATP (PerkinElmer) and various unlabeled nucleotides. Mixture aliquots were spotted onto Polygram CEL-300 PEI sheets (Macherey-Nagel), separated by TLC with $0.75 \mathrm{~mol} / \mathrm{L} \mathrm{KH}_{2} \mathrm{PO}_{4}(\mathrm{pH}$ 3.5) as solvent and developed by autoradiography. Nucleotidase activities were also assayed in peripheral lymph nodes, spleen, and sera from wild-type and $A p o e^{-/-}$mice, as described previously. ${ }^{24}$

\section{Plasma ATP, ADP, and Hemoglobin Measurements}

Plasma ATP and ADP were determined using an ATPlite assay kit with a long-lived luminescent signal (PerkinElmer, Groningen, the Netherlands) under the conditions delineated experimentally, as described under Results. Briefly, 4- $\mu \mathrm{L}$ aliquots of EDTA plasma were transferred into two parallel wells of a white nonphosphorescent 96well microplate containing $100 \mu \mathrm{L}$ of PBS with ("A") or without ("B") mixture of $200 \mu \mathrm{mol} / \mathrm{L}$ UTP and $5 \mathrm{U} / \mathrm{mL}$ of NDPK from baker's yeast Saccharomyces cerevisiae (Sigma). Subsequent to addition of $50 \mu \mathrm{L}$ of ATP-monitoring reagent, the luminescence of the samples was measured using a Tecan Infinite M200 microplate reader (Salzburg, Austria). The difference in luminescence signals between wells $A(A T P+A D P)$ and $B$ (only ATP) allowed quantification of the concentration of ADP, which was converted into ATP through the NDPK-mediated reaction in the presence of exogenous UTP. Plasma hemoglobin concentration was also determined by measuring the absorbance at the peak of the Soret band $(415 \mathrm{~nm})$ and also at 380 and $450 \mathrm{~nm}$, as described elsewhere. ${ }^{27}$ Plasma samples showing elevated hemoglobin levels were excluded from further analysis.

\section{Statistical Analysis}

Data from kinetic studies were subjected to computer analyses using the Michaelis-Menten equation to determine the $K_{\mathrm{m}}$ and $V_{\max }$ values (GraphPad Prism 4.03 software; San Diego, CA). Data sets were examined by analysis of variance, and the significance level was set at $P<0.05$. 
A

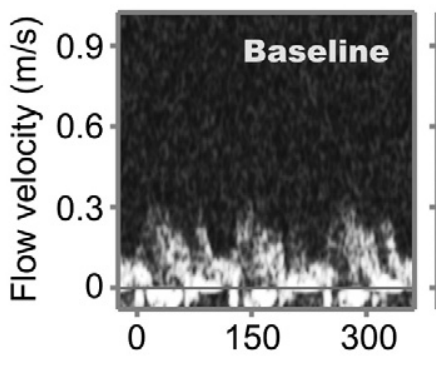

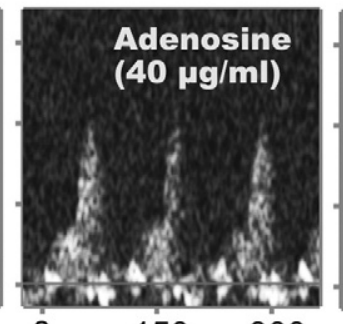

150

Time (ms)
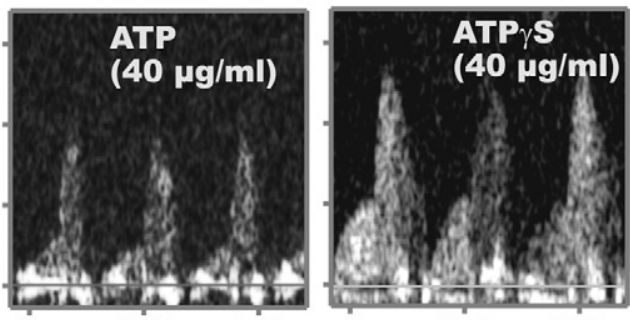

$\mathrm{B}$

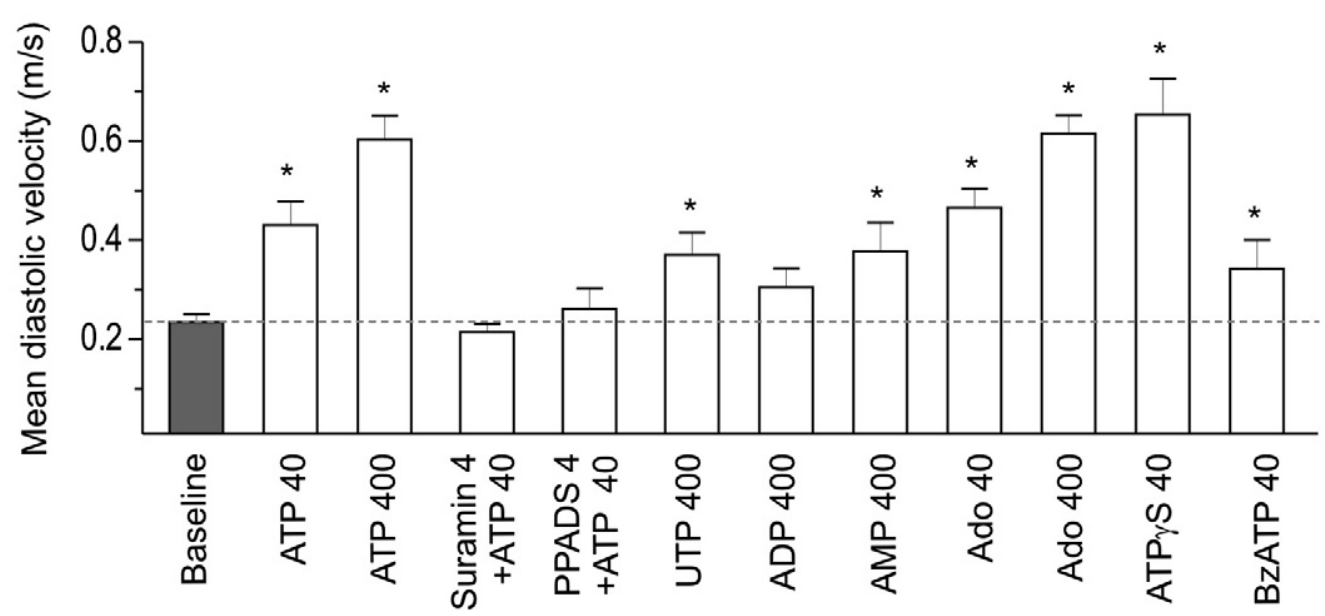

Figure 1. Coronary blood flow velocity in $\mathrm{C} 57 \mathrm{Bl} / 6$ mice at rest and during hyperemia. A: Representative coronary flow velocity profiles obtained with pulsed-wave Doppler from the middle left coronary artery at rest (baseline) and during infusion of $40 \mu \mathrm{g} / \mathrm{mL}$ of adenosine, ATP and ATP $\gamma \mathrm{S}$. B: The indicated doses $(\mu \mathrm{g} / \mathrm{mL})$ of different nucleotides, nucleotide analogues, and adenosine (Ado) were administered into the tail veins of $\mathrm{C} 57 \mathrm{Bl} / 6 \mathrm{mice}$ for $\sim 2 \mathrm{minutes}$ at the flow rate of $0.6 \mathrm{~mL} /$ hour, and their vasoactive potency was determined by measuring the mean diastolic flow velocity (mean \pm SEM; $n=3$ to 6 ). In certain assays, the mice were pre-treated for 3 minutes with P2 antagonists PPADS or suramin $(4 \mu \mathrm{g} / \mathrm{mL})$ before infusion of ATP. ${ }^{*} P<0.05$ versus basal blood flow measured in the absence of treatment.

\section{Results}

\section{ATP Induces Hyperemia in Mice through Activation of Own P2Y Receptors Rather Than via Its Dephosphorylation to Adenosine}

To evaluate the role of purinergic signaling in coronary artery vasodilation, we took advantage of noninvasive TTDE. Blood flow velocity in the middle left coronary artery was analyzed by defining flow velocity profiles in pulsed-wave Doppler images, both at baseline and hyperemic conditions induced by various purinergic agents (Figure 1A). Infusion of 40 to $400 \mu \mathrm{g} / \mathrm{mL}$ ATP into the tail vein was accompanied by progressive increase in the coronary blood flow, which can be prevented by pretreatment of the animals with the nonselective P2 antagonists PPADS and suramin (Figure 1B). Note, infusion of vehicle (saline solution), PPADS, or suramin alone does not induce any hyperemic responses (data not shown). A significant increase in the blood flow was observed during infusion of adenosine, with maximal vasodilation reached at a dose of $400 \mu \mathrm{g} / \mathrm{mL}$, whereas equimolar concentrations of UTP and AMP (but not ADP) caused less profound responses (Figure 1B). We also tested the vasoactive potencies of ATP $\gamma$ S, a nonhydrolyzable P2Y agonist with preferential selectivity for $\mathrm{P}_{2} \mathrm{Y}_{2}$ receptors, ${ }^{8,15}$ as well as BzATP, which primarily binds to $P 2 X_{7}$ with partial agonistic potency against other P2X and P2Y receptors. ${ }^{8}$ As shown in Figure 1, ATP $\gamma S$ and, to a lesser extent, BzATP triggered significant increases in the coronary blood flow. Strikingly, contrary to the transient vasoactive effects of ATP and other purines in which blood flow rapidly returned to baseline values after terminating the treatment, the completion of ATP $\gamma S$ infusion to the mice was followed by continuously elevated blood flow for at least 10 ensuing minutes. Collectively, these data suggest that the hyperemic effects of ATP are mainly mediated through the activation of ATP/UTP-specific $\mathrm{P}_{2} \mathrm{Y}_{2}$ receptors rather than via nucleotide dephosphorylation to adenosine.

\section{Coronary Flow Velocity Is Diminished in} Apoe $^{-I-}$ Mice in Response to ATP, but Not to Adenosine

Further comparative analysis of the heart rate (Figure 2A) and basal coronary flow (Figure 2B) did not show any differences in cardiovascular parameters at resting conditions between the wild-type and $A p o e^{-/-}$mice. CFR was then assessed by measuring the ratio between coronary blood flow before and during pharmacologically induced vasodilation. Induction of hyperemia by infusion of ATP revealed clear-cut distinctions manifested as sig- 
A

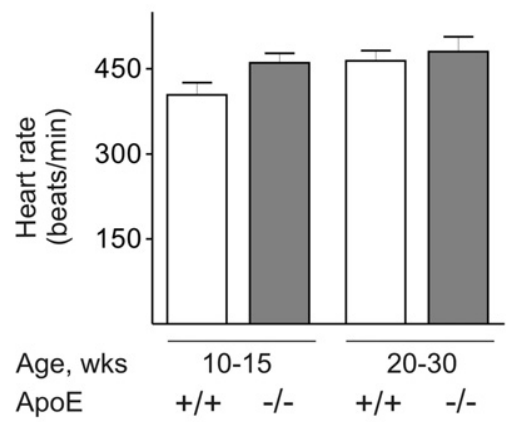

B

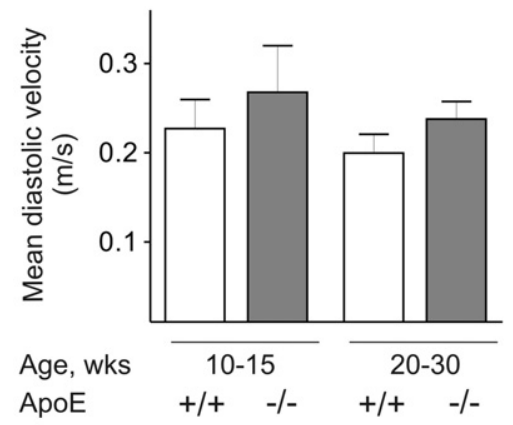

C

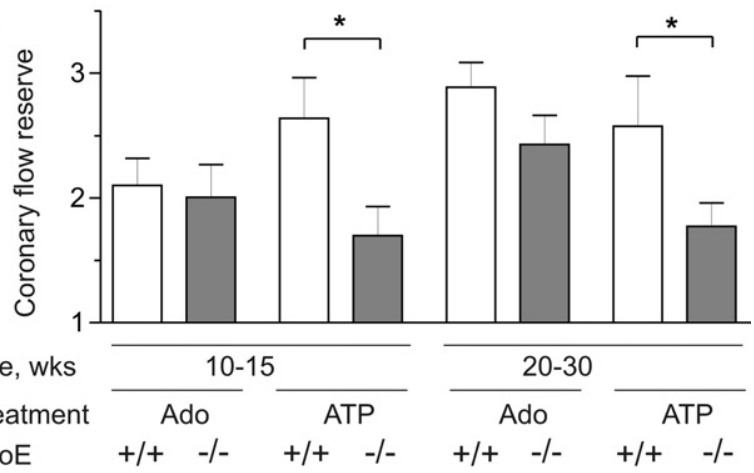

Figure 2. $A p o e^{-/-}$mice display impaired hyperemic responses to ATP, but not adenosine. Heart rate (A) and mean diastolic velocity (B) were determined in young (10- to 15-week-old) and mature (20- to 30-week-old) $A p o e^{-1-}$ mice and their age-matched $\mathrm{C} 57 \mathrm{Bl} / 6$ controls $\left(A p o e^{+/+}\right)$using TTDE. C: Exogenous adenosine and ATP were administered into the tail veins of the mice at dose of $40 \mu \mathrm{g} / \mathrm{mL}$ and CFR was calculated as the ratio of mean diastolic velocities before and during infusion of vasoactive purines. Data are presented as mean $\pm \operatorname{SEM}(n=6$ to 7$)$. ${ }^{*} P<0.05$ versus wild-type controls.

nificantly impaired CFR both in the young and mature Apoe $^{-/-}$mice (Figure 2C) without any changes in the heart rate (data not shown). Importantly, no differences in hyperemic velocities were determined between $\mathrm{Apoe}^{-/-}$ and wild-type mice during infusion of adenosine, another vasoactive purine (Figure $2 \mathrm{C}$ ), as well as during step changes in the concentration of the vasodilatory anesthetic gas isoflurane from $1.4 \%$ to $3 \%$ (data not shown).

\section{Nucleotide Metabolism in Murine Aorta Is Primarily Mediated by NTPDase1/CD39 Expressed on Vascular SMC}

Subsequent studies evaluated intravascular nucleotide metabolism in the wild-type and $A p o e^{-/-}$mice. Due to the inability to dissect and isolate coronary vessels in amounts sufficient for biochemical characterization, enzymatic activities were evaluated in thoracic aorta as another pertinent site of active atherogenesis. First, the distribution of nucleotidases in murine aortas was evaluated in situ by a lead precipitation method. The employment of ATP as a substrate revealed substantial ATPase activity in all aortic regions (Figure $3 \mathrm{~A}$ ), and a similar staining pattern was observed with other nucleoside triphosphates UTP and ITP (data not shown). In contrast, ADP staining was mainly restricted to endothelium and $S M C$, with less intense staining in the adventitia (Figure $3 A)$. These findings corroborate previous studies showing that ATP and ADP hydrolysis in murine aorta is primarily mediated by NTPDase1/CD39 abundantly expressed on SMC and other compartments, with a moderate contribution from another ATP-specific enzyme NTPDase2 to the "residual" ATP hydrolysis in the adventitia. ${ }^{15,28}$ Histochemical analysis with yet another nucleotide, AMP, shows a narrow and intense band primarily restricted to the vascular endothelium, with more faint and diffuse staining throughout the SMC (Figure 3A).

Specific activities were then assayed by TLC by using saturating concentrations of ${ }^{3} \mathrm{H}$-nucleotide substrates and total homogenates and different aortic fractions as enzyme sources. As shown in Figure 3B, the murine aorta is characterized by high rates of $\left[{ }^{3} \mathrm{H}\right] \mathrm{ATP}$ and $\left[{ }^{3} \mathrm{H}\right] \mathrm{ADP}$ hydrolysis with SMC NTPDase being the most abundant inactivating enzyme. Use of $\left[{ }^{3} \mathrm{H}\right] \mathrm{AMP}$ as initial substrate revealed only moderate $5^{\prime}$-nucleotidase activity in all aortic compartments studied. Additional competitive and substrate-specificity analyses with $\left[\gamma^{-}{ }^{32}\right.$ P]ATP and other ${ }^{3} \mathrm{H}$-labeled and unlabeled nucleotides revealed marked inhibition of ATPase and ADPase activities in the presence of the specific NTPDase 1 inhibitor POM-1 or $\mathrm{Ca}^{2+} /$ $\mathrm{Mg}^{2+}$-chelating agent EDTA and further demonstrated the coexistence of counteracting phosphorylating activities in murine aorta, namely adenylate kinase and NDPK (Figure 3B; see Supplemental Figure S1 at $h$ ttp://ajp. amjpathol.org). These data demonstrate that catabolism of ATP and ADP in murine aorta is mediated by the same cation-dependent enzyme, most likely NTPDase1/CD39, which is primarily derived from SMC and whose activity exceeds other purine-converting enzymes, NDPK, adenylate kinase, and 5'-nucleotidase, by $\sim 2,9$, and 25 times, respectively.

\section{NTPDase Activity Is Decreased in Thoracic Aorta, but Not in Lymphoid Tissues and Serum, of Apoe ${ }^{-1-}$ Mice}

Major nucleotidases were then assayed in aortas from $A_{p o e^{-/-}}$mice and further compared with control activities in age-matched C57BI/6 mice. Both ATPase and ADPase were diminished by $\sim 40 \%$ to $50 \%$ in young $A_{p o e^{-/-}}$mice, with the latter activity remaining significantly down-regulated in mature animals (Figure 4A). Additional kinetic analysis of the rate of $\left[{ }^{3} \mathrm{H}\right] \mathrm{ADP}$ hydrolysis versus substrate concentration shows that, in comparison with wild-type controls, the aortas from young 
A
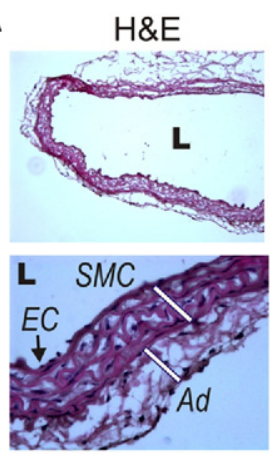
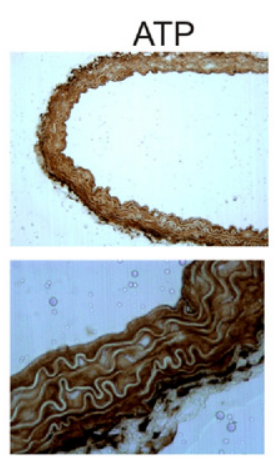
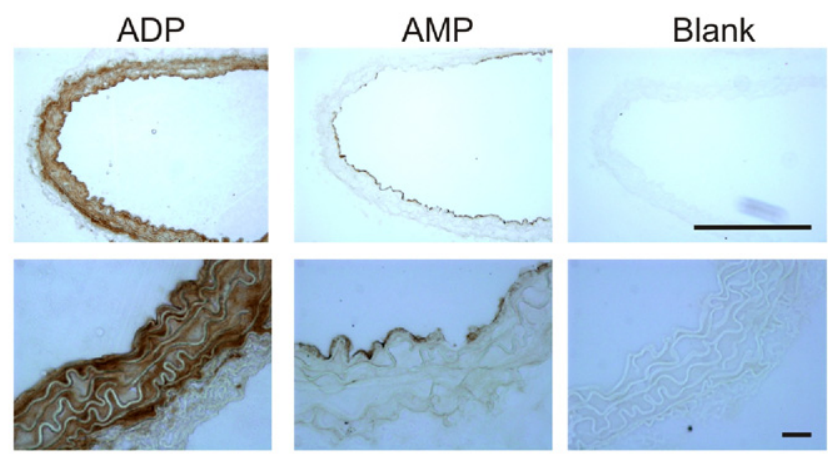

B
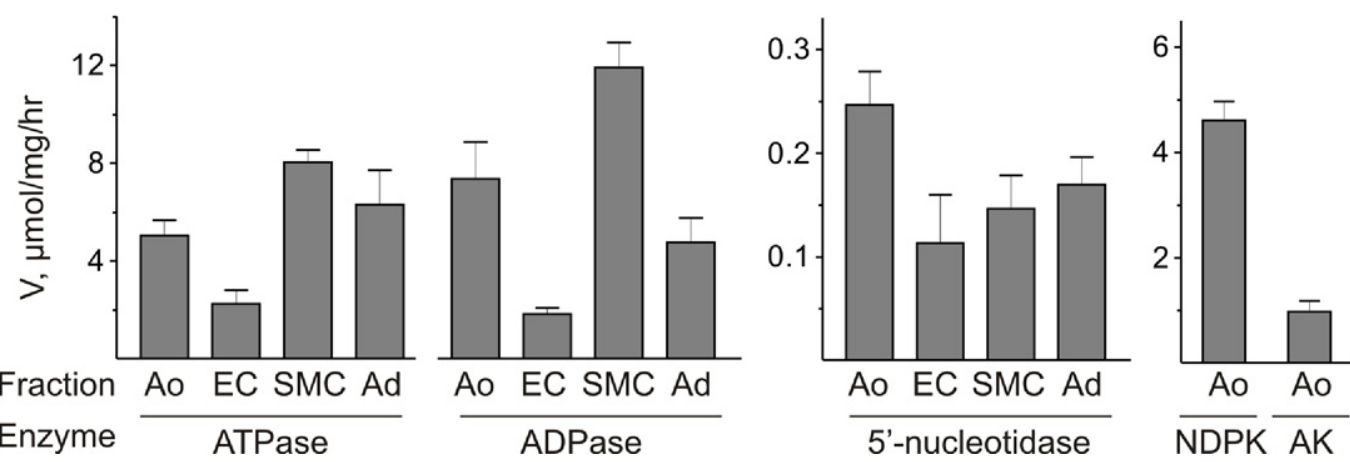

Figure 3. Distribution of nucleotidase activities in thoracic aorta from $\mathrm{C} 57 \mathrm{Bl} / 6$ mice. A: Enzyme histochemical staining of aortic sections was performed in the absence (blank) and presence of nucleotide substrates ATP, ADP $(300 \mu \mathrm{mol} / \mathrm{L})$ and AMP $(1 \mathrm{mmol} / \mathrm{L})$. Tissue sections were also stained with hematoxylin and eosin (H\&E). Scale bars: $100 \mu \mathrm{m}$. Original magnification: $\times 100$ and $\times 400$ for upper and lower panels, respectively. B: ATPase, ADPase, $5^{\prime}$-nucleotidase, NDPK, and adenylate kinase (AK) were assayed in total aortic homogenate, as well as in different fractions by TLC using ${ }^{3} \mathrm{H}-\mathrm{labeled}$ and unlabeled nucleotides. Enzyme activities are expressed as $\mu$ moles of ${ }^{3} \mathrm{H}$-substrate metabolized by $1 \mathrm{mg}$ protein per hour. Fractions from aortas of three mice were pooled to obtain one specimen, and data show mean \pm SEM from three independent experiments. Ad, adventitia; Ao, aorta; EC, endothelial cells; L, lumen; SMC, smooth muscle cells.

Apoe $^{-/-}$mice display diminished maximal velocity $\left(V_{\max }\right)$ without any changes in the apparent $K_{m}$ value (see Supplemental Figure S2 at http://ajp.amjpathol.org). These data indicate a decreased number of NTPDase molecules in $A p o e^{-1-}$ mice without conformational changes of the enzyme catalytic site. The activity of yet another enzyme, ecto-5'-nucleotidase, remained comparable in all studied aortic specimens (Figure 4A). In principle, lymphoid and/or soluble enzymes may also contribute to the intravascular nucleotide homeostasis. ${ }^{24,26}$ However, measurement of nucleotidase activities in the peripheral lymph nodes, spleen, and serum did not reveal any differences between $A p o e^{-1-}$ and wild-type mice (see Supplemental Figure S3 at $h t t p: / /$ ajp.amjpathol.org).

To test the possibility that decreased aortic NTPDase might be due to development of lipid-rich plaques, aortas from wild-type and $A p o e^{-1-}$ mice were stained with Oil Red O. Relatively mild lesions were detected in the aortic roots and arches and to a lesser extent in the proximal thoracic aortas of mature adult, but not in young, Apoe $e^{-/-}$mice (Figure 4B). Further quantitative analysis confirmed that the percentage of whole aortic surface area occupied by the lesions increased with age accounting for $0.55 \% \pm 0.09 \%(n=$ $22)$ and $3.11 \% \pm 0.61 \%(n=15)$ in young and mature Apoe $^{-1-}$ mice, respectively (Figure 4C). These results are consistent with previous observations showing that, subsequent to early foam cell formation at age of
10 to 15 weeks, more advanced aortic lesions with larger necrotic cores and abundant fibrous tissue are developed in older 20- to 40-week-old Apoe -1- $^{\text {mice. }}{ }^{5}$

\section{Circulating ATP and ADP Are Elevated in Plasma from Mature, but Not Young, Apoe ${ }^{-1-}$ Mice}

Data on disordered nucleotide homeostasis in $A p o e^{-/-}$ mice prompted us to further investigate whether circulating ATP and ADP levels are concurrently shifted in these atherosclerotic-prone animals. For this purpose, a sensitive enzyme-coupled assay was devised where ADP reacts with exogenously applied UTP in the presence of NDPK to generate UDP and ATP, with the latter nucleotide being measured by a coupled luciferin/luciferase reaction (Figure 5A). Because the measured ATP represents the integral value for ATP+ADP concentrations, ATP was recorded in parallel without UTP/NDPK reaction mixture and this value was subtracted from the above signal to yield ADP-dependent bioluminescence. Such an approach allows simultaneous measurement of both ATP and ADP content within the same sample. No shifts in plasma ATP (Figure 5B) and ADP (Figure 5C) were detected in young $A p o e^{-/-}$mice, whereas plasma from mature $A p o e^{-1-}$ mice contained significantly elevated levels of both nucleotides. Plasma hemoglobin was concurrently used as an index of blood hemolysis, which might potentially affect ATP concentrations due to addi- 
A
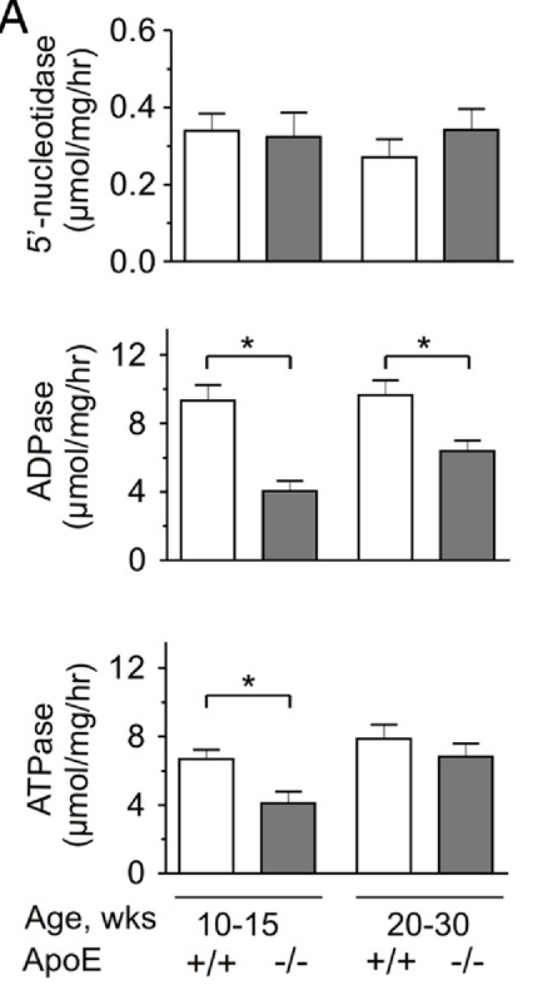

B
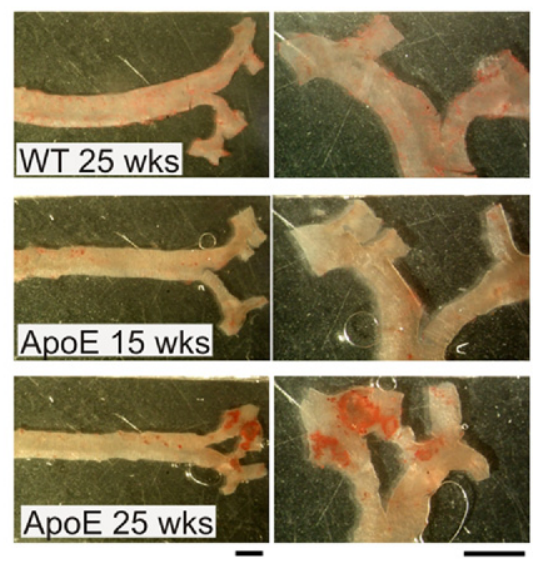

C

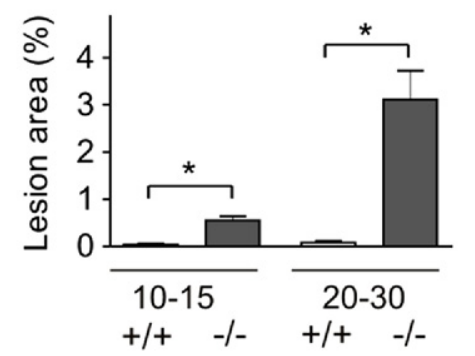

Figure 4. Pattern of nucleotide catabolism and plaque development in aortas from $A p o e^{-1}$ mice. A: ATPase, ADPase, and 5'-nucleotidase were determined in aortic homogenates from young and mature $A p o e^{-/-}$and wild-type $\left(\right.$ Apo $\left.^{+/++}\right)$mice. Data are presented as mean \pm SEM ( $n \geq 10$ for each group). B: Representative photomicrographs of Oil Red O staining in thoracic roots of longitudinally opened aortas are shown for 25-week-old wild-type (WT) as well as in 15- and 25-week-old Apoe $e^{-1-}$ mice. Scale bars: $2 \mathrm{~mm}$. C: Red lesion areas stained with Oil Red $\mathrm{O}$ were quantified in aortas from young and mature $A p o e^{-1-}$ and wild-type mice and presented as a percentage of total aortic area (mean \pm SEM, $n>0$ ). ${ }^{*} P<0.05$ as compared with wild-type controls. tional nucleotide release from the formed elements during blood sampling. ${ }^{27}$ No differences in plasma hemoglobin were detected among the wild-type and $A_{p o e^{-1-}}$ mice (Figure 5D).

\section{Discussion}

By investigating the combined features of coronary blood flow and intravascular nucleotide homeostasis in animals prone to the disease but still essentially healthy, this study provides evidence for the contribution of purinergic mechanisms to the abnormal vasoreactivity at the onset of atherosclerosis. Salient findings are that, compared to control C57BI/6 mice, Apoe ${ }^{-1-}$ mice are characterized by impaired coronary vasodilation in response to ATP, but not adenosine, and a diminished nucleotide-inactivating capability of the thoracic aorta due to down-regulation of NTPDase1/CD39.

In clinical studies, decreased CFR in response to adenosine (assessed by TTDE, positron emission tomography, and other imaging techniques) is generally associated with an elevated risk of major adverse cardiovascular events, such as death, hospitalization due to acute coronary syndromes, and myocardial infarction. ${ }^{19,29}$ Another purinergic agent, ATP, has also been used as a diagnostic tool for assessing the blood flow in patients with coronary artery diseases. ${ }^{30,31}$ Although earlier studies have treated the vasoactive effects of ATP and adenosine as being identical, it is becoming evident that ATP may exert vasodilation via a dual mechanism including activation of nucleotide-selective $\mathrm{P}_{2} \mathrm{Y}_{1}$ and/or $\mathrm{P}_{2} \mathrm{Y}_{2}$ receptors $^{10,32,33}$ and further conversion to adenosine and activation of $A_{2 A}$ and, to some extent, $A_{2 B}$ receptors on vascular endothelium and SMC. ${ }^{29}$ This concept offers the pleasing feature of biological economy by using a single molecule acting multiple times at disparate receptor sites within the vessel to achieve the local regulation of blood flow. ${ }^{32}$

The present TTDE study with adenosine, ATP, other nucleotides, and various nonhydrolyzable $\mathrm{P} 2$ receptor agonists and antagonists also provides evidence that ATP regulates coronary blood flow in mice via direct activation of its own $\mathrm{P} 2 \mathrm{Y}$ receptors, most likely of the $\mathrm{P} 2 \mathrm{Y}_{2}$ subtype. Strikingly, young Apoe ${ }^{-/-}$mice were shown to display significantly impaired CFR in response to ATP, but not to the other vasoactive agents, adenosine, and isoflurane. Notably, the young (10- to 15-week-old) and mature (20- to 30-week-old) Apoe ${ }^{-1-}$ mice used in this study develop only negligible and mild plaques in the thoracic aorta, respectively ( ${ }^{5,6}$; see also Figure 4 ), yet without any signs of stenosis and lesion formation in the epicardial coronary arteries or other changes in cardiovascular physiology. ${ }^{34,35}$ Therefore, our observation that adenosine-induced vasodilation remains unchanged in the wild-type and Apoe ${ }^{-1-}$ mice reasonably suggest that previously reported impaired hyperemic responses to adenosine in 1- to 2-year-old Apoe ${ }^{-/-21}$ and $\mathrm{Ldlr}^{-/-}$ Apob48 ${ }^{-1-23}$ mice with severe atherosclerosis were mainly defined by coronary artery narrowing rather than because of impaired adenosinergic signaling pathways. On the other hand, this study represents the first indication that ATP-mediated control of coronary blood flow is disturbed in young Apoe ${ }^{-/-}$mice, thereby serving as one of the critical events preceding lesion development and 
A

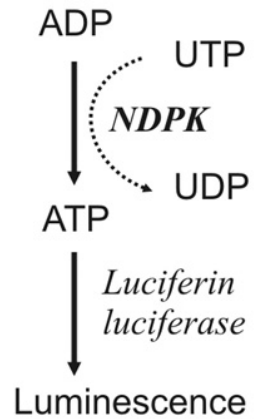

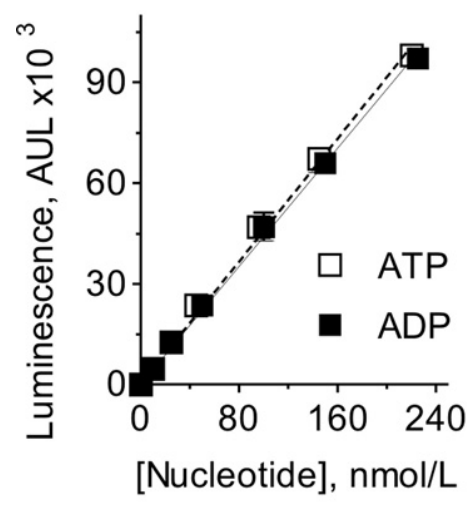

B

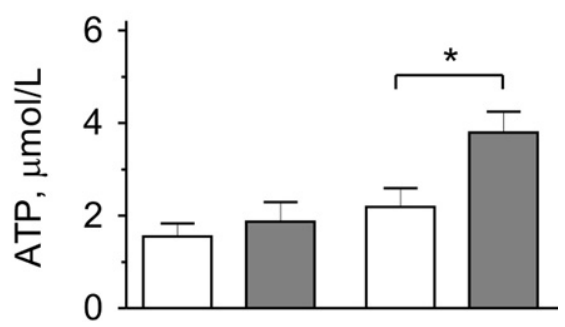

C

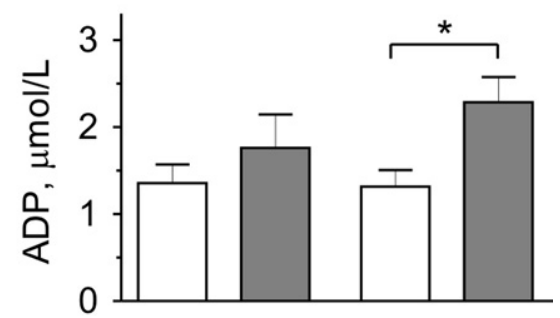

D

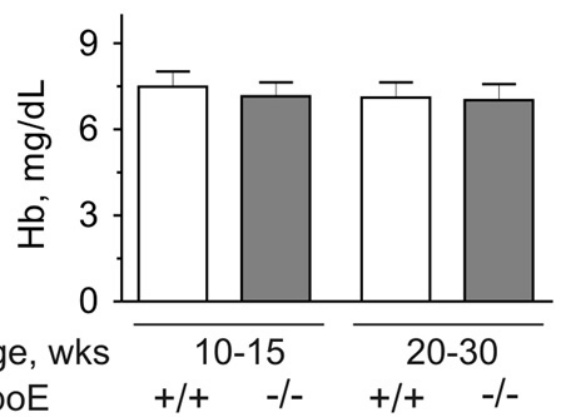

Figure 5. ATP, ADP, and hemoglobin levels in plasma from wild-type and $A p o e^{-/-}$mice. A: A luciferin-luciferase assay was devised for the simultaneous determination of ATP and ADP, with the latter nucleotide being detected by NDPKmediated transphosphorylation of ADP into ATP in the presence of exogenous UTP. Calibration curves were generated for each experiment using identical coupled reactions with PBS containing ATP/ADP standards. ATP (B), ADP (C) and hemoglobin (D) were determined in EDTAplasma using appropriate bioluminescent and spectrophotometric techniques. Data are presented as mean $\pm \operatorname{SEM}(n=19$ to 25$) .{ }^{*} P<0.05$ versus age-matched $\mathrm{C} 57 \mathrm{Bl} / 6$ controls. occlusion of the lumen of coronary artery, which are the hallmarks of human coronary heart diseases.

Because murine atherosclerosis is mainly associated with development of severe plaques in thoracic aorta, the majority of previous studies with $A p o e^{-1-}$ mice were focused on mechanisms of aortic lesion formation and accompanying risk factors, such as hypercholesterolemia, hypertension, and inflammation. ${ }^{7}$ Specifically, recent proteomic and metabolomic analysis of aortas from 10week-old $\mathrm{Apoe}^{-/-}$mice revealed that increased oxidative stress and inefficient energy metabolism preceded plaque formation in these hyperlipidemic animals. ${ }^{36}$ Moreover, both basal level of $\left[\mathrm{Ca}^{2+}\right]_{i}$ and ATP-induced store-operated $\mathrm{Ca}^{2+}$ release remain constitutively elevated in the aorta of young plaque-free $A p o e^{-1-}$ mice. ${ }^{37}$ Interestingly, although similar $\mathrm{P}_{2} \mathrm{Y}_{1}$ and $\mathrm{P}_{2} \mathrm{Y}_{2}$ receptor profiles have been reported in thoracic aortas and aortic arches from 4-month-old $A p o e^{-1-}$ and wild-type mice, ${ }^{38}$ in comparison with Apoe $e^{-1-}$ mice, a $P 2 y 1^{-1-} / A p o e^{-1-}$ double knockout mice was shown to develop $\sim 40 \%$ fewer atherosclerotic lesions at week 17, and this difference disappeared at week $30 .^{39}$

Subsequent to the signal transduction, intravascular nucleotides need to be rapidly inactivated to adenosine. Data presented here, in conjunction with previous immunofluorescent and histochemical stainings in wild-type and Entpd1 ${ }^{-1-}$ mice, ${ }^{15,28}$ provide evidence for the presence of an extensive network of nucleotide-converting activities in murine aorta, with SMC NTPDase1/CD39 be- ing the most abundant ATP- and ADP-hydrolyzing enzyme. Furthermore, an important novelty of this study is that the activity of NTPDase1/CD39 is significantly downregulated in aorta from $A p o e^{-/-}$mice without any differences in other lymphoid or soluble nucleotidase activities. Data on diminished aortic nucleotide metabolism in young $A p o e^{-1-}$ mice provide another insight into the current concepts of the proatherogenic role of ATP at the onset of disease. Although no changes in circulating ATP and ADP were detected in plasma from young Apoe - $^{-1}$ mice (Figure 5), we do not exclude the possibility that diminished aortic NTPDase in these pre-atherosclerotic animals may account for transiently elevated ATP and ADP levels at potentially atherogenic regions which, in turn, disturbs the tuned control of vascular tone. Likewise, previous studies have shown that Entpd $1^{-\prime-}\left(\mathrm{CD}^{-1} 9^{-\prime}\right)$ mice are characterized by disordered hemostasis and shifts in the immune and pro-coagulant responses without any systemic changes in plasma ATP and ADP, which primarily occur due to local accumulation of extracellular nucleotides and desensitization of $\mathrm{P}_{2} \mathrm{Y}_{1}$ and, to a lesser extent, $\mathrm{P}_{2} \mathrm{Y}_{2}$ receptors. ${ }^{12,40}$

The exact mechanisms of decreased aortic NTPDase remain unknown. One explanation may be the increased oxygen demand and formation of a local hypoxic environment in atherogenic regions with disturbed flow pattern and enhanced endothelial turnover, such as brunch points, bifurcations, and curvatures. ${ }^{20}$ In this context, it is relevant to mention that cell-surface NTPDases exist ei- 
ther in monomeric or homo-oligomeric states and various factors affecting their oligomerization state (eg, oxidative cross-linking, treatment with detergents) would trigger marked loss of nucleotidase activity. ${ }^{14,41}$ Vascular endothelial NTPDase1/CD39 was shown to be diminished and even lost under various conditions of inflammatory or oxidant stress, including long-term hypoxic exposure, ${ }^{42}$ ischemia reperfusion injury, and transplantation. ${ }^{13}$ Significantly decreased expression of NTPDases, but not ecto$5^{\prime}$-nucleotidase, has also been demonstrated in blood vessels from abdominal aortas of patients with atherosclerosis or atherosclerosis-like diseases, such as abdominal aneurysm, Leriche syndrome, or myocardial infarction. ${ }^{43}$ In addition to their transient effects on vascular tone, extracellular ATP and other nucleotides (UTP, UDP, ADP) are involved in long-term trophic effects on cell growth and proliferation $n^{2,8,42}$ and can mediate a shift from a specialized contractile vascular SMC phenotype into a proliferating matrix-producing phenotype.,10 Given the broad substrate specificity of NTPDases toward various nucleoside di- and triphosphates, ${ }^{11,14}$ it may be anticipated that the diminished aortic enzyme activity in $A p o e^{-1-}$ mice is also related to the development of intimal thickening via enhanced nucleotide-mediated migration and proliferation of SMC in the arterial media.

In summary, the contribution of arterial wall nucleotide turnover to atherosclerosis seems to be more complicated than envisaged earlier. Although the impaired coronary vasodilatory responses to ATP and down-regulated aortic NTPDase activity occurred in different vascular beds, this study, for the first time, provides evidence that disturbed purinergic signaling pathways are among the earliest alterations in young hyperlipidemic and pre-atherosclerotic $\mathrm{Apoe}^{-/-}$mice. These shifts in nucleotide homeostasis could, in turn, lead to local accumulation of ATP and ADP at sites of atherogenesis, desensitization of P2-receptors, disturbed blood flow, sustained triggering of chronic proinflammatory responses, and eventually, the exacerbation of atherosclerosis and atheroma progression.

\section{Acknowledgments}

We thank Sari Mäki, Pia Rantakari, and Camilla Tallgren for technical assistance, Anne Sovikoski-Georgieva for secretarial help, and Dr. David Smith for the revision of the text.

\section{References}

1. Ross R: Atherosclerosis: an inflammatory disease. $N$ Engl J Med 1999, 340:115-126

2. Di Virgilio F, Solini A: P2 receptors: new potential players in atherosclerosis. Br J Pharmacol 2002, 135:831-842

3. Hansson GK: Inflammation, atherosclerosis, and coronary artery disease. N Engl J Med 2005, 352:1685-1695

4. Mahley RW, Rall SC Jr.: Apolipoprotein E: far more than a lipid transport protein. Annu Rev Genomics Hum Genet 2000, 1:507-537

5. Nakashima Y, Plump AS, Raines EW, Breslow JL, Ross R: Apoedeficient mice develop lesions of all phases of atherosclerosis throughout the arterial tree. Arterioscler Thromb 1994, 14:133-140
6. Meir KS, Leitersdorf E: Atherosclerosis in the apolipoprotein-E-deficient mouse: a decade of progress. Arterioscler Thromb Vasc Biol 2004, 24:1006-1014

7. Zadelaar S, Kleemann R, Verschuren L, de Vries-Van der Weij J, van der Hoorn J, Princen HM, Kooistra T: Mouse models for atherosclerosis and pharmaceutical modifiers. Arterioscler Thromb Vasc Biol 2007, 27:1706-1721

8. Ralevic V, Burnstock G: Receptors for purines and pyrimidines. Pharmacol Rev 1998, 50:413-492

9. Seye Cl, Kong Q, Yu N, Gonzalez FA, Erb L, Weisman GA: P2 receptors in atherosclerosis and postangioplasty restenosis. Purinergic Signal 2006, 2:471-480

10. Erlinge D, Burnstock G: $P 2$ receptors in cardiovascular regulation and disease. Purinergic Signal 2008, 4:1-20

11. Yegutkin GG: Nucleotide- and nucleoside-converting ectoenzymes: important modulators of purinergic signalling cascade. Biochim Biophys Acta 2008, 1783:673-694

12. Pinsky DJ, Broekman MJ, Peschon JJ, Stocking KL, Fujita T, Ramasamy R, Connolly ES Jr., Huang J, Kiss S, Zhang Y, Choudhri TF, McTaggart RA, Liao H, Drosopoulos JH, Price VL, Marcus AJ, Maliszewski CR: Elucidation of the thromboregulatory role of CD39/ectoapyrase in the ischemic brain. J Clin Invest 2002, 109:1031-1040

13. Robson SC, Wu Y, Sun X, Knosalla C, Dwyer K, Enjyoji K: Ectonucleotidases of CD39 family modulate vascular inflammation and thrombosis in transplantation. Semin Thromb Hemost 2005, 31:217-233

14. Robson SC, Sevigny J, Zimmermann H: The E-NTPDase family of ectonucleotidases: structure function relationship and pathophysiological significance. Purinergic Signal 2006, 2:409-430

15. Kauffenstein G, Furstenau CR, D'Orleans-Juste P, Sevigny J: The ecto-nucleotidase NTPDase1 differentially regulates P2Y1 and P2Y2 receptor-dependent vasorelaxation. Br J Pharmacol 2010, 159:576585

16. Zernecke A, Bidzhekov K, Ozuyaman B, Fraemohs L, Liehn EA, Luscher-Firzlaff JM, Luscher B, Schrader J, Weber C: CD73/ecto-5'nucleotidase protects against vascular inflammation and neointima formation. Circulation 2006, 113:2120-2127

17. Wong CW, Christen T, Roth I, Chadjichristos CE, Derouette JP, Foglia BF, Chanson M, Goodenough DA, Kwak BR: Connexin37 protects against atherosclerosis by regulating monocyte adhesion. Nat Med 2006, 12:950-954

18. Chadjichristos CE, Scheckenbach KE, van Veen TA, Richani Sarieddine MZ, de Wit C, Yang Z, Roth I, Bacchetta M, Viswambharan H, Foglia B, Dudez T, van Kempen MJ, Coenjaerts FE, Miquerol L, Deutsch U, Jongsma HJ, Chanson M, Kwak BR: Endothelial-specific deletion of connexin 40 promotes atherosclerosis by increasing CD73-dependent leukocyte adhesion. Circulation 2010, 121:123-131

19. Kiviniemi T: Assessment of coronary blood flow and the reactivity of the microcirculation non-invasively with transthoracic echocardiography. Clin Physiol Funct Imaging 2008, 28:145-155

20. Chiu JJ, Chien S: Effects of disturbed flow on vascular endothelium: pathophysiological basis and clinical perspectives. Physiol Rev 2011, 91:327-387

21. Wikström J, Grönros J, Gan LM: Adenosine induces dilation of epicardial coronary arteries in mice: relationship between coronary flow velocity reserve and coronary flow reserve in vivo using transthoracic echocardiography. Ultrasound Med Biol 2008, 34:1053-1062

22. Hartley CJ, Reddy AK, Madala S, Michael LH, Entman ML, Taffet GE: Effects of isoflurane on coronary blood flow velocity in young, old and Apoe(-/-) mice measured by Doppler ultrasound. Ultrasound Med Biol 2007, 33:512-521

23. Saraste A, Kytö V, Laitinen I, Saraste M, Leppänen P, Ylä-Herttuala S, Saukko P, Hartiala J, Knuuti J: Severe coronary artery stenoses and reduced coronary flow velocity reserve in atherosclerotic mouse model: Doppler echocardiography validation study. Atherosclerosis 2008, 200:89-94

24. Yegutkin GG, Hytönen J, Samburski SS, Yrjänäinen $H$, Jalkanen $S$, Viljanen MK: Disordered lymphoid purine metabolism contributes to the pathogenesis of persistent Borrelia garinii infection in mice. J Immunol 2010, 184:5112-5120

25. Braun N, Sevigny J, Robson SC, Hammer K, Hanani M, Zimmermann $\mathrm{H}$ : Association of the ecto-ATPase NTPDase2 with glial cells of the peripheral nervous system. Glia 2004, 45:124-132

26. Yegutkin GG, Samburski SS, Jalkanen S: Soluble purine-converting enzymes circulate in human blood and regulate extracellular ATP 
level via counteracting pyrophosphatase and phosphotransfer reactions. FASEB J 2003, 17:1328-1330

27. Gorman MW, Marble DR, Ogimoto K, Feigl EO: Measurement of adenine nucleotides in plasma. Luminescence 2003, 18:173-181

28. Kauffenstein G, Drouin A, Thorin-Trescases N, Bachelard H, Robaye B, D'Orleans-Juste P, Marceau F, Thorin E, Sevigny J: NTPDase1 (CD39) controls nucleotide-dependent vasoconstriction in mouse. Cardiovasc Res 2010, 85:204-213

29. Mustafa SJ, Morrison RR, Teng B, Pelleg A: Adenosine receptors and the heart: role in regulation of coronary blood flow and cardiac electrophysiology, Handb Exp Pharmacol 2009, (193):161-188

30. Miyagawa M, Kumano S, Sekiya M, Watanabe K, Akutzu H, Imachi T, Tanada S, Hamamoto K: Thallium-201 myocardial tomography with intravenous infusion of adenosine triphosphate in diagnosis of coronary artery disease. J Am Coll Cardiol 1995, 26:1196-1201

31. Hosaka M, Takagi A, Takagi T, Ashihara K, Hagiwara N: Strain measurements during adenosine triphosphate infusion before and after percutaneous coronary intervention, Circ J 2010, 74:1600-1608

32. Buxton IL, Kaiser RA, Oxhorn BC, Cheek DJ: Evidence supporting the Nucleotide Axis Hypothesis: aTP release and metabolism by coronary endothelium. Am J Physiol Heart Circ Physiol 2001, 281:H1657H1666

33. Rosenmeier JB, Yegutkin GG, Gonzalez-Alonso J: Activation of ATP/ UTP-selective receptors increases blood flow and blunts sympathetic vasoconstriction in human skeletal muscle. J Physiol 2008, 586:49935002

34. Zhang SH, Reddick RL, Piedrahita JA, Maeda N: Spontaneous hypercholesterolemia and arterial lesions in mice lacking apolipoprotein E. Science 1992, 258:468-471

35. Chase A, Jackson CL, Angelini GL, Suleiman MS: Coronary artery disease progression is associated with increased resistance of hearts and myocytes to cardiac insults. Crit Care Med 2007, 35:2344-2351
36. Mayr M, Chung YL, Mayr U, Yin X, Ly L, Troy H, Fredericks S, Hu Y, Griffiths JR, Xu Q: Proteomic and metabolomic analyses of atherosclerotic vessels from apolipoprotein E-deficient mice reveal alterations in inflammation, oxidative stress, and energy metabolism. Arterioscler Thromb Vasc Biol 2005, 25:2135-2142

37. Van Assche T, Fransen P, Guns PJ, Herman AG, Bult H: Altered $\mathrm{Ca} 2+$ handling of smooth muscle cells in aorta of apolipoprotein E-deficient mice before development of atherosclerotic lesions. Cell Calcium 2007, 41:295-302

38. Guns PJ, Hendrickx J, Van Assche T, Fransen P, Bult H: P2Y receptors and atherosclerosis in apolipoprotein E-deficient mice. Br J Pharmacol 2010, 159:326-336

39. Hechler B, Freund M, Ravanat C, Magnenat S, Cazenave JP, Gachet C: Reduced atherosclerotic lesions in P2Y1/apolipoprotein E doubleknockout mice: the contribution of non-hematopoietic-derived P2Y1 receptors. Circulation 2008, 118:754-763

40. Enjyoji K, Sevigny J, Lin Y, Frenette PS, Christie PD, Esch JS 2nd, Imai M, Edelberg JM, Rayburn H, Lech M, Beeler DL, Csizmadia E, Wagner DD, Robson SC, Rosenberg RD: Targeted disruption of cd39/ATP diphosphohydrolase results in disordered hemostasis and thromboregulation. Nat Med 1999, 5:1010-1017

41. Knowles AF: The GDA1_CD39 superfamily: nTPDases with diverse functions. Purinergic Signal 2011, 7:21-45

42. Yegutkin G, Helenius M, Kaczmarek E, Burns N, Jalkanen S, Stenmark K, Gerasimovskaya EV: Chronic hypoxia impairs extracellular nucleotide metabolism and barrier function in pulmonary artery vasa vasorum endothelial cells, Angiogenesis 2011, 14:503513

43. Lecka J, Bloch-Boguslawska E, Molski S, Komoszynski M: Extracellular purine metabolism in blood vessels (part II): activity of ectoenzymes in blood vessels of patients with abdominal aortic aneurysm. Clin Appl Thromb Hemost 2010, 16:650-657 